\title{
OPEN The heavy chain of 4F2 antigen promote prostate cancer progression via SKP-2
}

\author{
Maihulan Maimaiti ${ }^{1,2,9}$, Shinichi Sakamoto ${ }^{1,9 凶}$, Masahiro Sugiura ${ }^{1,3}$, Manato Kanesaka ${ }^{1,3}$, \\ Ayumi Fujimoto ${ }^{1}$, Keisuke Matsusaka ${ }^{4}$, Minhui Xu ${ }^{5}$, Keisuke Ando ${ }^{1,6}$, Shinpei Saito ${ }^{1,6}$, \\ Ken Wakai ${ }^{1,2}$, Yusuke Imamura ${ }^{1}$, Keiichi Nakayama ${ }^{7}$, Yoshikatsu Kanai ${ }^{5}$, Atsushi Kaneda ${ }^{3}$, \\ Yuzuru Ikehara ${ }^{2}$, Jun-Ichiro Ikedaa ${ }^{8}$, Naohiko Anzai ${ }^{6}$ \& Tomohiko Ichikawa $^{1}$
}

The 4F2 cell-surface antigen heavy chain ( $4 \mathrm{~F} 2 \mathrm{hc}$ ) forms a heterodimeric complex with L-type amino acid transporter 1 (LAT1) and transports large neutral essential amino acids. However, in contrast to the traditional role of LAT1 in various cancers, the role of 4F2hc has largely remained unknown. The role of $4 \mathrm{~F} 2 \mathrm{hc}$ in prostate cancer was studied. Treatment of $\mathrm{C4}-2$ cells with si4F2hc was found to suppress cellular growth, migratory and invasive abilities, with this effect occurring through the cell cycle, with a significant decrease in S phase and a significant increase in G0/G1 phase, suggesting cell cycle arrest. In addition, it was proven by RNA seq that the key to 4F2hc's impact on cancer is SKP2. si4F2hc upregulates the protein expression of cyclin-dependent kinase inhibitors (P21cip1, P27kip1) through the downstream target SKP2. Furthermore, the expression of 4F2hc and LAT1 in prostate cancer cells suggests the importance of 4F2hc. Multivariate analysis showed that high 4F2hc expression was an independent prognostic factor for progression-free survival (HR 11.54, $p=0.0357$ ). High 4F2hc was related to the clinical tumour stage $(p=0.0255)$ and Gleason score $(p=0.0035)$. Collectively, 4F2hc contributed significantly to prostate cancer (PC) progression. 4F2hc may be a novel marker and therapeutic target in PC.

Prostate cancer (PC) is the most commonly diagnosed malignancy and one of the most frequently diagnosed cancers in men $^{1,2}$. Despite progress in the treatment of localized PC, management of locally advanced and metastatic disease is still a critical unmet need ${ }^{3,4}$. Androgen deprivation therapy (ADT) is the standard treatment for advanced $\mathrm{PC}^{2}$. However, the clinical benefit of ADT is only temporary, and it has always evolved into castration-resistant prostate cancer (CRPC) with different treatments ${ }^{5,6}$. A new generation of androgen receptor (AR)-targeting agents has been developed, such as the androgen biosynthesis inhibitor abiraterone and the AR inhibitor enzalutamide, and they have been shown to improve overall survival $(\mathrm{OS})^{6,7}$. However, treatment resistance remains a significant challenge for CRPC. Some reports showed major improvement with abiraterone and enzalutamide treatment, whereas there was no decrease in serum prostate-specific antigen (PSA) levels ${ }^{8,9}$. Thus, a novel no-AR therapeutic approach and biomarker candidates for CRPC remain a significant issue.

Cancer cells require substantial amounts of nutrients to grow and multiply, especially cancer cells that have lost normal reproductive function. Amino acids are essential nutrients that are transported to the cell by a selective transporter on the plasma membrane ${ }^{10-12}$. Amino acid transporters are required for tumour growth and proliferation. Several lines of evidence have shown that nutrient transporters are upregulated in cancer cells while supporting large-scale growth and reproduction ${ }^{13}$.

L-type amino acid transporter 1 (LAT1, SLC7A5), a systemic L amino acid transporter, requires a covalent association with $4 \mathrm{~F} 2$ cell-surface antigen heavy chain (4F2hc,SLC3A2) for its functional expression in the

${ }^{1}$ Department of Urology, Chiba University Graduate School of Medicine, 1-8-1 Inohana, Chuo-ku, Chiba City, Chiba 260-8670, Japan. 'Department of Tumor Pathology, Chiba University Graduate School of Medicine, Chiba, Japan. ${ }^{3}$ Department of Molecular Oncology, Chiba University Graduate School of Medicine, Chiba, Japan. ${ }^{4}$ Department of Pathology, Chiba University Hospital, Chiba, Japan. ${ }^{5}$ Bio-System Pharmacology, Osaka University Graduate School of Medicine, Osaka, Japan. ${ }^{6}$ Department of Pharmacology, Chiba University Graduate School of Medicine, Chiba, Japan. ${ }^{7}$ Department of Molecular and Cellular Biology, Medical Institute of Bioregulation, Kyushu University, Fukuoka, Japan. ${ }^{8}$ Department of Diagnostic Pathology, Graduate School of Medicine, Chiba University, Chiba, Japan. ${ }^{9}$ These authors contributed equally: Maihulan Maimaiti and Shinichi Sakamoto. ${ }^{\boxplus}$ email: rbatbat1@gmail.com 
plasma membrane ${ }^{14}$. LAT1, which has been shown to bind to $4 \mathrm{~F} 2 \mathrm{hc}$, is abundantly expressed in various types of cancers, including non-small cell lung cancer, breast cancer, biliary tract cancer, pancreatic cancer, and prostate cancer ${ }^{15-19}$. Besides LAT1, several studies have shown an association between higher 4F2hc expression levels and worse prognosis in various types of cancer $^{20-22}$. In addition, we recently identified $4 \mathrm{~F} 2 \mathrm{hc}$ as one of the main target genes for AR-V7. Upregulation of 4F2hc through AR-V7 contributes to the progression of CRPC ${ }^{23}$.

Based on the above-described findings, it may be reasonable to expect that $4 \mathrm{~F} 2 \mathrm{hc}$ is a promising prognostic biomarker, as well as a molecular target, in PC. In this study, the oncogenic function of $4 \mathrm{~F} 2 \mathrm{hc}$ in $\mathrm{PC}$ and its relationship with the clinical outcome of PC patients was studied.

\section{Results}

Analysis of 4F2hc expression and 4F2hc knockdown in PC cell lines. In PC cell lines, the highest 4F2hc protein expression was observed in DU145 cells, followed by PC-3 and C4-2 cells (Fig. 1A) $(p=0.0061$, $p=0.0804, p=0.0026$, and $p=0.0200$; respectively). Compared with LAT1 expression, significantly higher $4 \mathrm{~F} 2 \mathrm{hc}$ expression was observed in C4-2 and DU145 cells (Fig. 1B) ( $p=0.0014$ and $p=0.0020$; respectively). According to the basal expression level in Fig. 1A, C 4-2 and DU145 cells were used for subsequent functional analysis. The expression levels of si4F2hc (si4F2hc-1 and si4F2hc-2) were significantly decreased in C4-2 and DU145 cells compared with those in the Negative Control (Nega) (Fig. 1C,E) (D: $p=0.0026$ and $p=0.0043 ; \mathrm{D}: p=0.0034$ and $p=0.0017$; respectively).

The functional role of $4 \mathrm{~F} 2 \mathrm{hc}$ in PC. Si4F2hc suppresses cell proliferation, migration, and invasion. Levels of 4F2hc mRNA were significantly suppressed following transfection of C4-2 and DU145 cells with si4F2hc (si4F2hc-1 and si4F2hc-2) compared with mock-transfected cells or those transfected with Nega. The si4F2hc (si4F2hc-1 and si4F2hc-2)-transfected cells showed significant growth reduction compared to the Nega (Fig. 2A,B) (A: $p=0.0131$ and $p=0.0012$; B: $p=0.0177$ and $p=0.0033$; respectively). Furthermore, si4F2hctransfected cells also demonstrated significant decreases in migration (Fig. 2C) $(p=0.0075$ and $p=0.0003$; D: $p=0.0011$ and $p=0.0050$; respectively) and invasion (Fig. $2 \mathrm{E})(p=0.0027$ and $p=0.0015 ; \mathrm{F}: p=0.0079$ and $p=0.0073$; respectively) activities compared with Nega (Fig. $2 \mathrm{C}-\mathrm{F}$ ). Cell migration activity was evaluated with wound healing assays. (Fig. S1A) ( $p=0.0031$ and $p=0.0150$; B: $p=0.0066$ and $p=0.0087$; respectively).

Analyse downstream genes by RNA-seq. To further elucidate the mechanism underlying inhibition by si4F2hc, the gene target and downstream signals of si4F2hc were investigated. A comparative RNA-seq analysis was performed using si4F2hc (si4F2hc-1 and si4F2hc-2) and Nega. Figure 3A shows a heat map of changes in the RNA-seq analysis under the influence of si4F2hc. In order to make the heat map more concrete, the most downregulated 1403 genes are selected, and Gene ontology (GO) analysis was performed using Metascape (http:// www.metascape.org). These commonly downregulated genes were markedly associated with the cell cycle ($\log 10=43.84)$, DNA replication $(-\log 10=26.75)$, and cell division $(-\log 10=23.88)$ (Fig. 3B). Confirmation of target genes downregulated at the top of the cell cycle was performed by real-time PCR analysis. Finally, SKP2 was identified as a target gene of 4F2hc (Fig. 3C). To study the functional role of SKP2, the growth of siSKP2transfected cells was monitored for five days. The increase in SiSKP2 (siSKP2-1 and siSKP2-2)-transfected cells was significantly reduced compared to Nega (Fig. 3D) $(p=0.0002$ and $p=0.0005$; respectively). We used C4-2 cells to evaluate RNA-seq results for identified genes (Fig. S2A). SiSKP2 (siSKP2-1 and siSKP2-2) inhibits DU145 cell proliferation (Fig. S2B) $(p=0.0076$ and $p=0.0084$; respectively).

In order to study the associations among 4Fhc, SKP2, and LAT1 expressions, the effects of si4F2hc on SKP2 and 4F2hc expressions and the effects of siSKP2 on 4F2hc and LAT1 expressions were studied. SKP2 and 4F2hc mRNA expressions were significantly lower in si4F2hc-transfected than in Nega (Fig. S3A to C) (A: $p=0.0011$ and $p=0.0010 ; \mathrm{B}: p=0.0116$ and $p=0.0021 ; \mathrm{C}: p=0.0155$ and $p=0.0097$; respectively). SKP2 mRNA expression was significantly lower in siSKP2-transfected than in Nega (Fig. S3, D) $(p=0.0019$ and $p=0.0028$; respectively). However, siSKP2 did not affect the expression of 4F2hc and LAT1 mRNA levels (Fig. S3E,F) (E: $p=0.1513$ and $p=0.02484 ; \mathrm{D}: p=0.2362$ and $p=0.6480$; respectively).

Validation of the association between $4 \mathrm{~F} 2 \mathrm{hc}$ and SKP2 expression by rescue assay. The skp2 overexpression by plasmid did not change the $4 \mathrm{~F} 2 \mathrm{hc}$ expression (Fig. S4A) $(p=0.0011, p=0.0031, p=0.0017, p=0.0027$; respectively). But the SKP2 plasmid caused SKP2 overexpression in the 4F2hc knockout group (Fig. S4B) $(p=0.0085$, $p=0.0026, p=0.0036, p=0.0226$; respectively). 4F2hc plasmid allowed $4 \mathrm{~F} 2 \mathrm{hc}$ overexpression (Fig. S4C) $(p=0.2015, p=0.1953, p=0.0012, p=0.0095$; respectively). The $4 \mathrm{~F} 2 \mathrm{hc}$ plasmid gave a slightly increased expression of SKP2 (Fig. S4D) ( $p=0.0005, p=0.0004, p=0.0008, p=0.0004$; respectively). The effect of the rescue assay was observed using cell proliferation. 4F2hc and SKP2 plasmids effectively accelerated cell proliferation (Fig. S4E,F).

Regulation of SKP2 and the cell cycle pathway by 4F2hc. Given the key function of SKP2 in the cell cycle and its molecular interplay with P21cip1 and P27cip1, a potential role of SKP2 in cell cycle progression was investigated. Treatment of C4-2 cells with si4F2hc-1 led to a significant decrease in the S phase and a substantial increase in the G0/G1 phase, suggesting cell cycle arrest (Fig. 4A-C). The percentage of si4F2hc-transfected cells was higher in the G0/G1 phase than in Nega-transfected cells (Fig. 4D). Next, whether 4F2hc regulation is associated with the expression of cyclin SKP2 in these cells and the regulation of the expression level or activation state of downstream signals were investigated. Western blot analysis showed significant downregulation of SKP2 in a state in which 4F2hc was inhibited, inhibition of phosphorylation of MAPK and AKT, and upregulation of protein expression by cyclin-dependent kinase inhibitors (P21cip1, P27kip1) (Fig. 4E). 
A
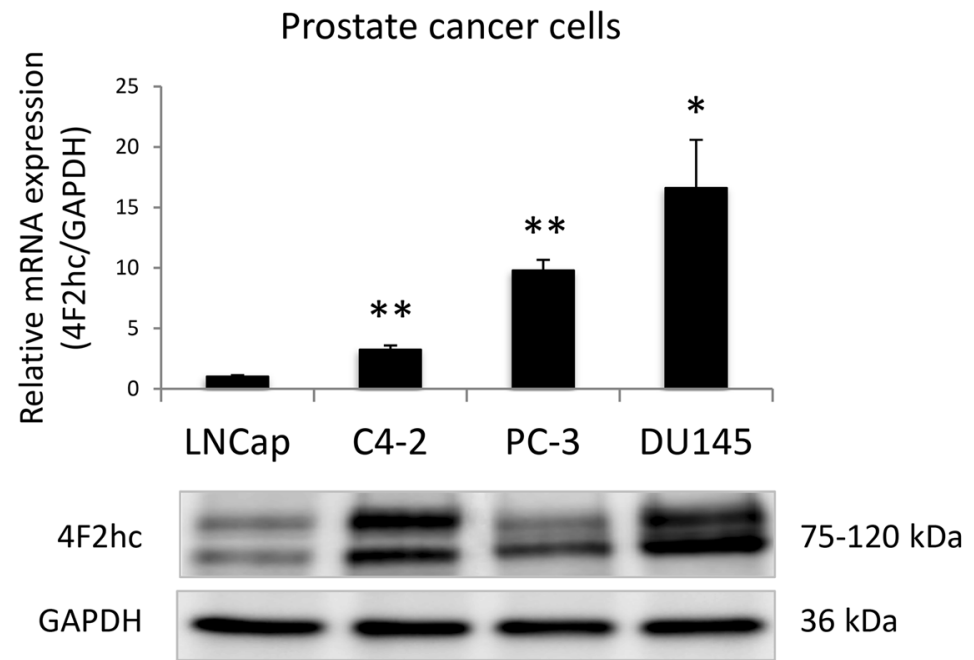

B Prostate cancer cells
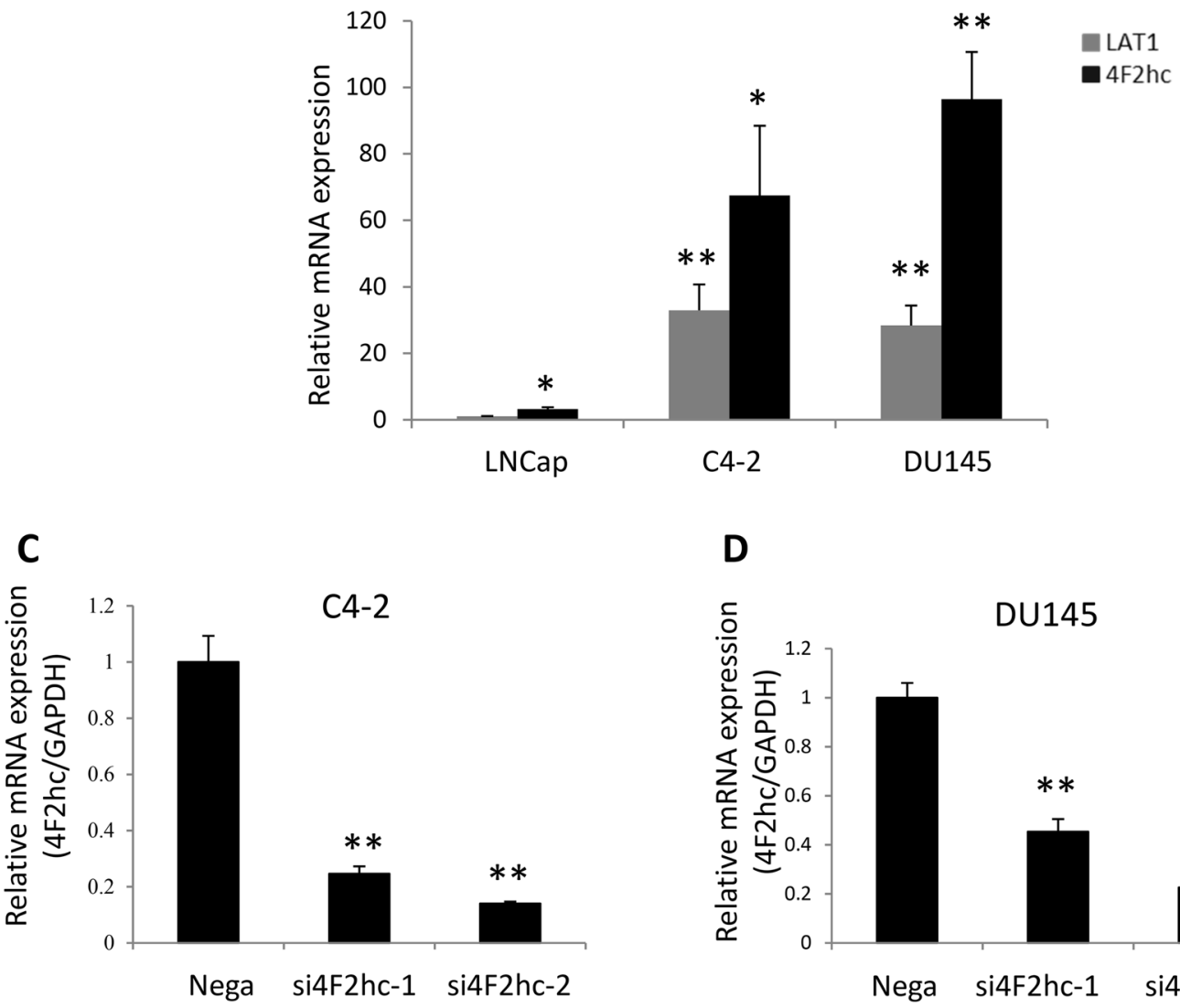

D

$4 \mathrm{~F} 2 \mathrm{hc}$

GAPDH
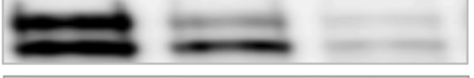

$75-120 \mathrm{kDa}$

\section{a}

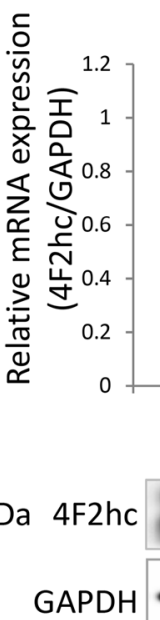

DU145

Figure 1. Expression of 4F2hc and LAT1 in PC cells and knocked down. Expression of 4F2hc in PC cells and functional significance of $4 \mathrm{~F} 2 \mathrm{hc}$ in PC cells. $4 \mathrm{~F} 2 \mathrm{hc}$ protein and mRNA levels were examined in PC cells (A). LAT1 mRNA and 4F2hc mRNA levels were examined in C4-2 and DU145 PC cells (B). Si4F2hc (si4F2hc-1 and si4F2hc-2) has significantly knocked down 4F2hc expression in C4-2 (C) and DU145 (D) cells. Nega indicates negative siRNA control. Data represent three independent experiments with similar results. P-values were calculated by the Mann-Whitney U-test. ${ }^{* *} p<0.01,{ }^{* * *} p<0.001$. 
A

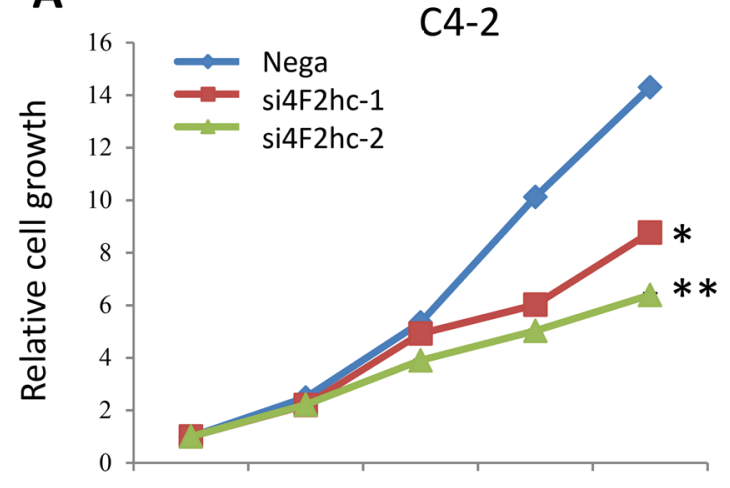

Day 1 Day 2 Day 3 Day 4 Day 5

C

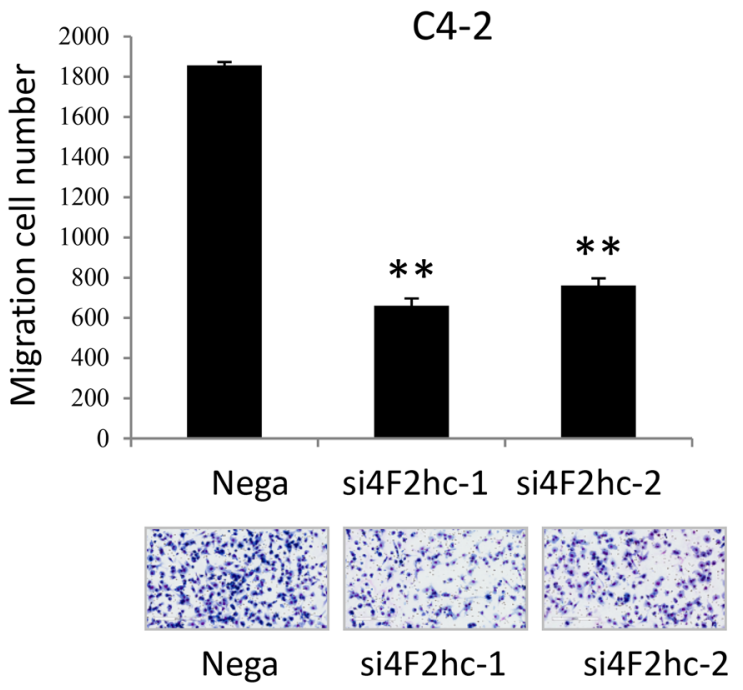

\section{$\mathbf{E}$}

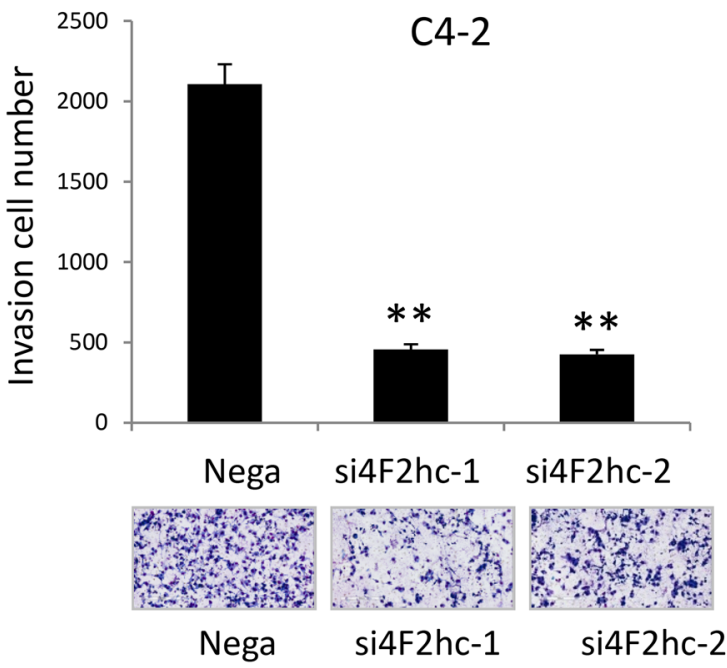

B

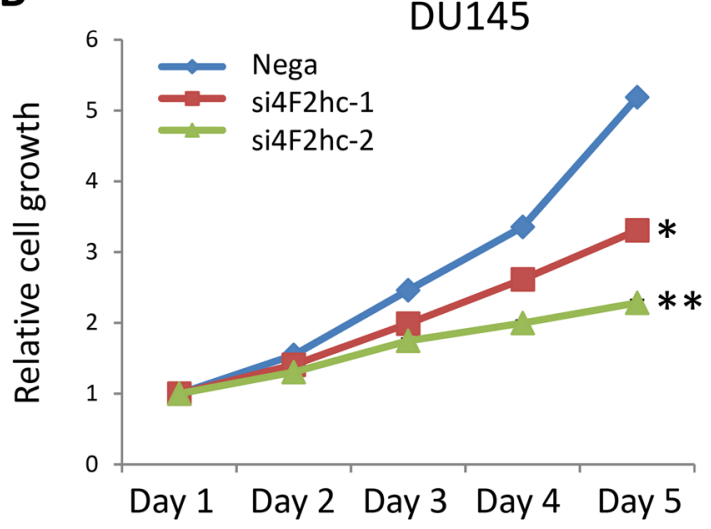

D

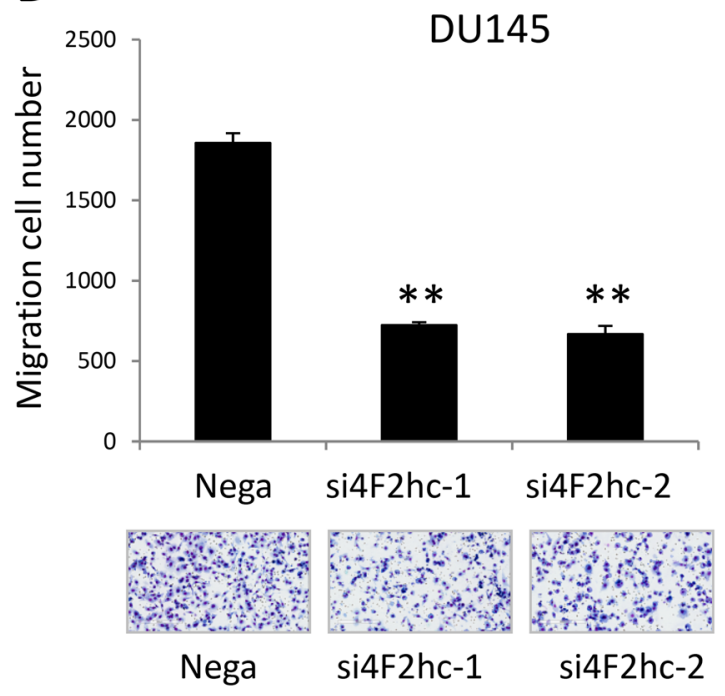

$\mathbf{F}$

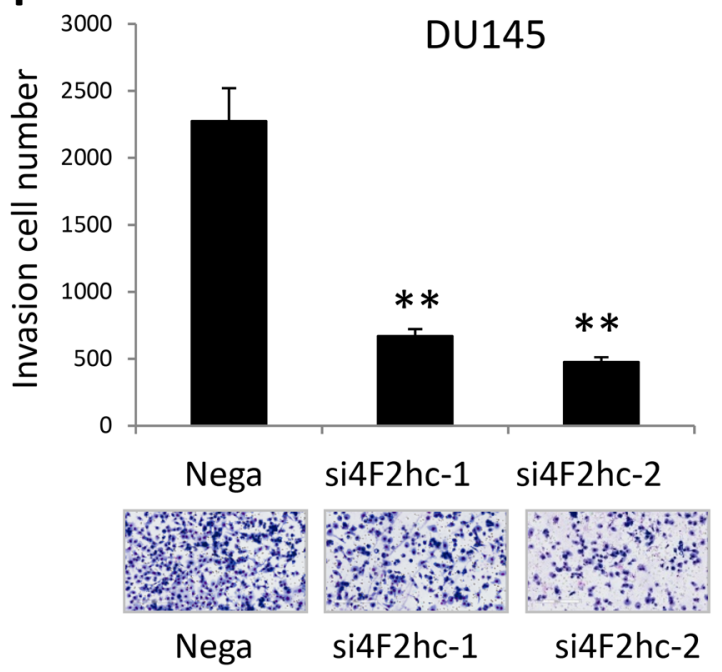

Figure 2. Functional significance of 4F2hc in DU145 and C4-2 cells. Si4F2hc (si4F2hc-1 and si4F2hc-2) inhibits C4-2 and DU145 cell proliferation (A,B), migration (C,D), and invasion (E,F). Nega indicates negative siRNA control. Data represent three independent experiments with similar results. P-values were calculated by the Mann-Whitney U-test. ${ }^{*} p<0.05,{ }^{* *} p<0.01$. 

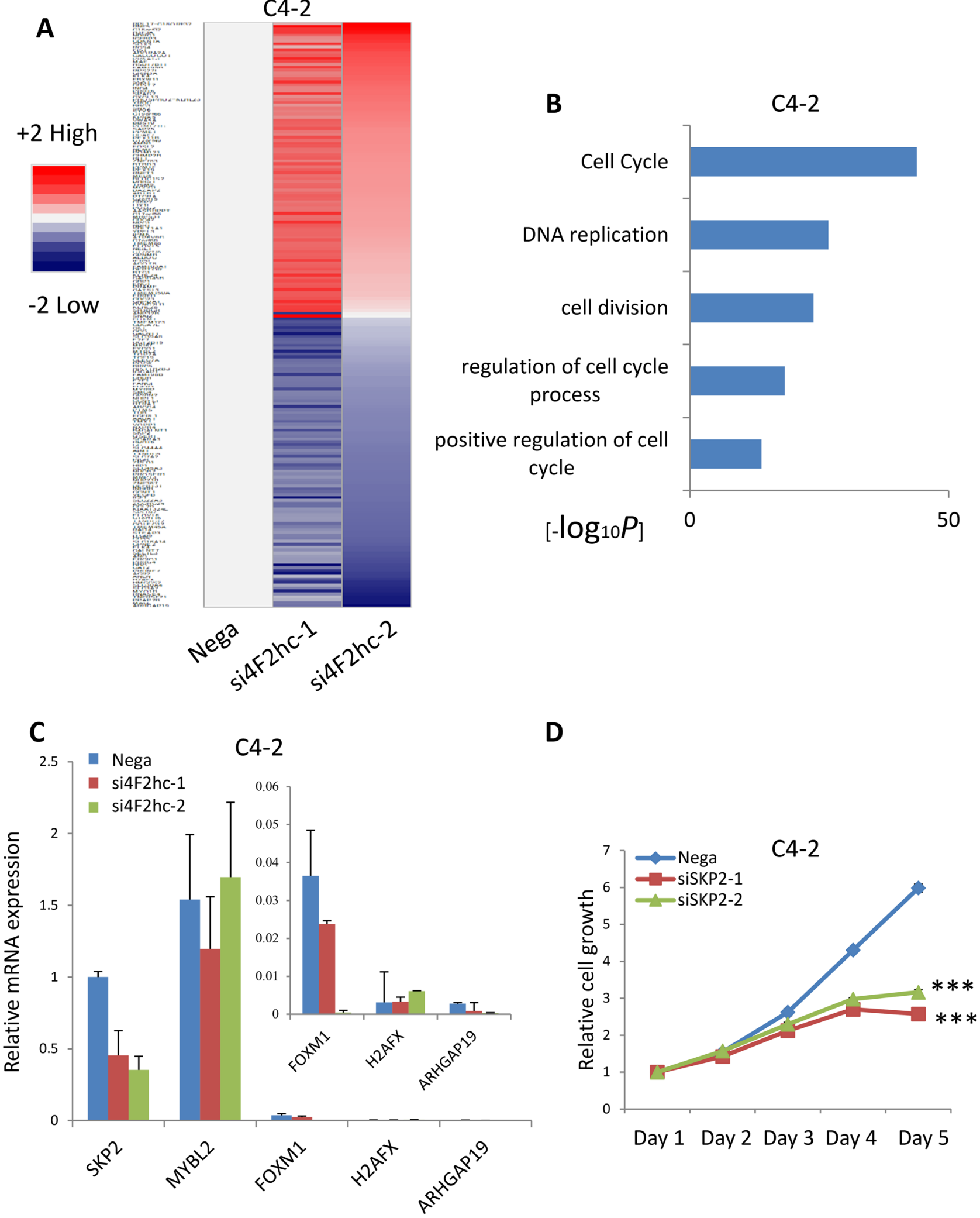

Figure 3. 4F2hc RNA-sequencing analysis. RNA-seq analysis was performed with si4F2hc (si4F2hc-1 and si4F2hc-2) and compared with a control group (A). The most down-regulated 1403 genes are selected, and Matascape is used for analysis of significantly related with GO terms (B). Si4F2hc concentration-dependent effect on candidate genes was assessed by real-time PCR (C). SiSKP2 (siSKP2-1 and siSKP2-2) inhibits C4-2 cell proliferation (D). Data represent three independent experiments with similar results. P-values were calculated by the Mann-Whitney U-test. ${ }^{* * *} p<0.001$. 

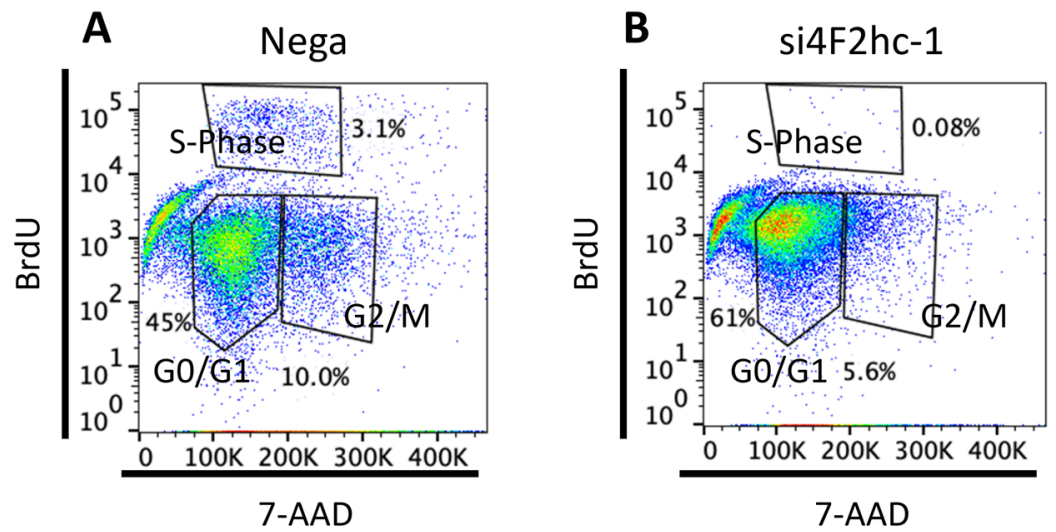

\section{C si4F2hc-2}

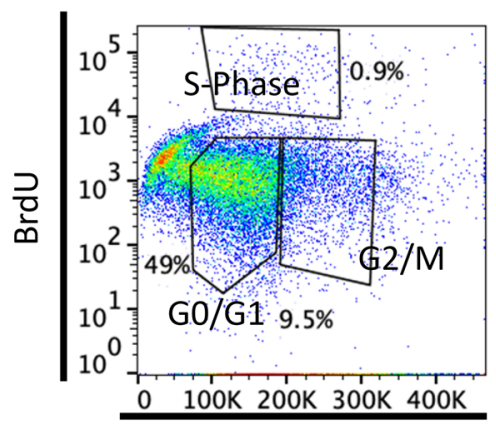

7-AAD
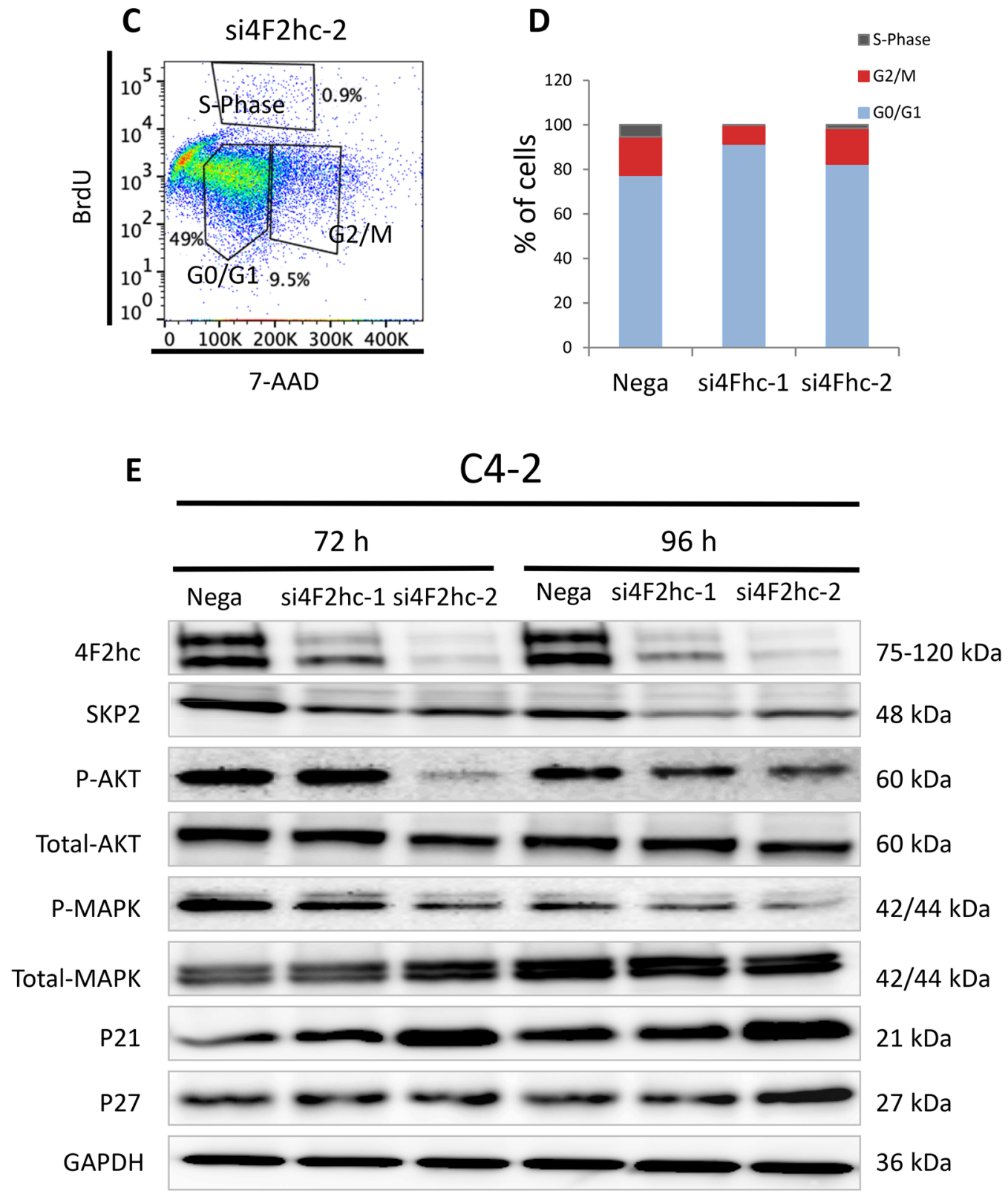

Figure 4. 4F2hc signalling pathway. Cell cycle analysis was performed with si4F2hc (si4F2hc-1 and si4F2hc-2) and compared with a control group (A to D). After $72 \mathrm{~h}$ or $96 \mathrm{~h}$, si4F2hc (si4F2hc-1 and si4F2hc-2) downregulation of SKP2, phosphorylation of AKT and MAPK, and increased expression of p21 and p27 (E). Data represent three independent experiments with similar results. 
4F2hc and LAT1 expression in PC tissue and association with clinical variables. The clinical significance of 4F2hc was further investigated, along with examination of 4F2hc expression in PC specimens, by IHC. Positive immunostaining for $4 \mathrm{~F} 2 \mathrm{hc}$ was detected in the cell membrane and cytoplasm. Intense immunostaining for $4 \mathrm{~F} 2 \mathrm{hc}$ was detected in cancerous lesions, whereas non-malignant lesions showed negative or weak immunostaining. Positive immunostaining for SKP2 was detected in the nucleus, mainly on the superficial central compartment of the tumour rather than in the tumour margins. The expression level of 4F2hc was studied by IHC. Positive immunostaining for $4 \mathrm{~F} 2 \mathrm{hc}$ was detected in the cell membrane and cytoplasm by PC specimens IHC. A strong 4F2hc immune response was detected in the cancer lesion's cell membrane, whereas normal adjacent tumour (NAT) mainly showed weak immunostaining. Regarding the 4F2hcIHC scores in NAT and PC lesions, NAT ranged from 0 to 150 (median $=20)$, whereas PC lesions ranged from 0 to 300 (median $=90)$. The $4 \mathrm{~F} 2 \mathrm{hc}$ IHC score was significantly higher in PC lesion than in NAT (Fig. $5 \mathrm{~A} ; p=0.0001$ ). Figure $5 \mathrm{~B}, \mathrm{C}$ are representative IHC result for 4F2hc and SKP2 staining. Sections were stained with haematoxylin and eosin (Fig. 5B; a: $600 \mu \mathrm{m} ; \mathrm{b}: 200 \mu \mathrm{m}$; and C; e: $600 \mu \mathrm{m}$; f: $200 \mu \mathrm{m}$ ), and representative images of 4F2hc IHC expression (Fig. 5C: $600 \mu \mathrm{m}$; d: $200 \mu \mathrm{m}$ ) and SKP2 IHC expression (Fig. 5G: $600 \mu \mathrm{m}$; h: $200 \mu \mathrm{m}$ ) are shown. LAT1 IHC is shown in Fig. S5. Sections were stained with haematoxylin and eosin (Fig. S5A: a: $600 \mu \mathrm{m}$; b: $200 \mu \mathrm{m}$ ), and representative images of LAT1 IHC expression are shown (Fig. S5c: $600 \mu \mathrm{m} ; \mathrm{d}: 200 \mu \mathrm{m})$.

Next, the prognostic clinical significance of $4 \mathrm{~F} 2 \mathrm{hc}$ and LAT1 expression was evaluated statistically. The patients' characteristics are listed in Table 1. Specimens were divided into two groups based on median 4F2hc and LAT1 IHC scores. The results showed that the high-4F2hc expression group showed significantly shorter progression-free survival (PFS) than the low 4F2hc expression group (Fig. 6A; $p=0.0034$ ). Although the high LAT1 expression group tended to show shorter survival, LAT1 expression was not related to PFS (Fig. S6A; $p=0.1085)$. When combining 4F2hc and LAT1 expression, the high 4F2hc/high LAT1 expression group showed the worst PFS $(p=0.0071)$, followed by the high $4 \mathrm{~F} 2 \mathrm{hc} /$ low LAT1 or low $4 \mathrm{~F} 2 \mathrm{hc} / \mathrm{high}$ LAT1 expression group (others) $(p=0.2297)$. In contrast, the low 4 F2hc/low LAT1 expression group showed good PFS (Fig. S6B).

Next, associations between clinicopathological characteristics and 4F2hc protein expression were investigated. On multivariate analysis, high $4 \mathrm{~F} 2 \mathrm{hc}$ expression (HR 11.54, $p=0.0357)$ and high clinical tumour stage (CT stage) (HR 4.22, $p=0.0280$ ) were also identified as independent prognostic factors for PFS (Table 2). The relationships between $4 \mathrm{~F} 2 \mathrm{hc}$ expression and various clinical factors were determined. High $4 \mathrm{~F} 2 \mathrm{hc}$ expression was associated with high age $(p=0.0162)$, high $c$ T stage $(p=0.0255)$, and high Gleason score (GS) $(p=0.0035)$ in PC patients (Table 3). However, high LAT1 expression was only associated with high GS $(p=0.0399)$ in PC patients (Table S1).

4F2hc and SKP2 expression in PC tissue and associations with clinical variables. The prognostic clinical significance of $4 \mathrm{~F} 2 \mathrm{hc}$ and SKP2 expressions was evaluated statistically. The high SKP2 expression group also showed a significantly shorter PFS (Fig. 6B; $p=0.0040$ ). When expressed in conjunction with 4F2hc and SKP2, the high $4 \mathrm{~F} 2 \mathrm{hc} / \mathrm{SKP} 2$ high expression group showed the worst PFS $(p=0.0017)$, followed by the high 4F2hc/low SKP2 or low 4F2hc/high SKP2 expression group (others) $(p=0.0623)$. In contrast, the low $4 \mathrm{~F} 2 \mathrm{hc} /$ low LAT1 expression group showed good PFS (Fig. 6C). The relationship between SKP2 expression and various clinical factors was determined. High SKP2 expression was associated with high cT stage $(p=0.0277)$, high GS $(p=0.0138)$, high PSA $(p=0.0458)$, and high PSAD $(p=0.0360)$ in PC patients (Table 4$)$.

To verify the reliability of our data, statistical analysis was performed using the Cancer Genome Atlas (TCGA) data. TCGA data and our data showed the similar results. The results showed that the High 4F2hc expression group also showed a significantly shorter PFS $(p=0.0369)$ (Fig. S7A). Similarly, the high-SKP2 expression group showed significantly shorter PFS than the low SKP2 expression group $(p=0.0088)$ (Fig. S7B), but LAT1 expression was not related to PFS ( $p=0.2166)$ (Fig. S7C). When combining 4F2hc and SKP2 expression, the low 4F2hc/ low SKP2 expression group showed good PFS. In contrast, the high 4F2hc/high LAT1 expression group showed the worst PFS $(p=0.0006)$ (Fig. S7D). When combining 4F2hc and LAT1 expression, the low 4F2hc/low LAT1 expression group showed good PFS ( $p=0.0273$ ) (Fig. S7E).

\section{Discussion}

The present study demonstrated several novel findings. 4F2hc expression seems to be one of the promising therapeutic targets in PC. Of the major clinical factors, including LAT1 expression, 4F2hc expression was the most significant prognostic factor in PC patients. The inhibition of $4 \mathrm{~F} 2 \mathrm{hc}$ function prevents the progression of several PC cell types. Furthermore, SKP2 was newly identified as a novel target of 4F2hc. Current evidence indicated the contribution of the cell cycle pathway as a central downstream mechanism of $4 \mathrm{~F} 2 \mathrm{hc}^{22,24}$

$4 \mathrm{~F} 2 \mathrm{hc}$ expression is increased in various human neoplasms, such as gastric cancer, pulmonary pleomorphic carcinoma, and neuroendocrine carcinoma ${ }^{20-22}$. Moreover, it has been reported that increased $4 \mathrm{~F} 2 \mathrm{hc}$ expression is significantly associated with shorter survival outcomes, cell proliferation, and metastasis ${ }^{25}$. $4 \mathrm{~F} 2 \mathrm{hc}$ binds with LAT1 on the membranous surface of cancer cells ${ }^{26}$. After the discovery of LAT1, it was also shown that the other five members of the solute carrier family 7 bind to $4 \mathrm{~F} 2 \mathrm{hc}$ as a light chain to form a different heterodimeric amino acid transporter. Heterodimerization is essential for its functional expression ${ }^{27}$. Interestingly, relevant research shows that ATF4 regulates 4F2hc, LAT1, and ASCT1 gene, with low expression in healthy prostate tissue and early prostate cancer. However, they are significantly increased in metastatic prostate cancer, indicating the essential nutrients required for transporters to promote metastatic prostate cancer ${ }^{28}$.

$4 \mathrm{~F} 2 \mathrm{hc}$ antigen is a heterodimeric protein composed of a glycosylated heavy chain $(120 \mathrm{kDa})$ and a nonglycosylated light chain $(75 \mathrm{kDa})^{14,29}$. The light and heavy chains were found to have unique biochemical functions. The heavy chain of CD98 is associated with functional integrin 4 and can regulate integrin activation through early T-cell antigen activation function ${ }^{30}$. Binding of $4 \mathrm{~F} 2 \mathrm{hc}$ to $\beta 1$ integrin has been reported to be specific. primarily by promoting cell spreading and tumorigenicity, a process that is mediated by stimulation of 
A

\section{Prostate cancer tissue}
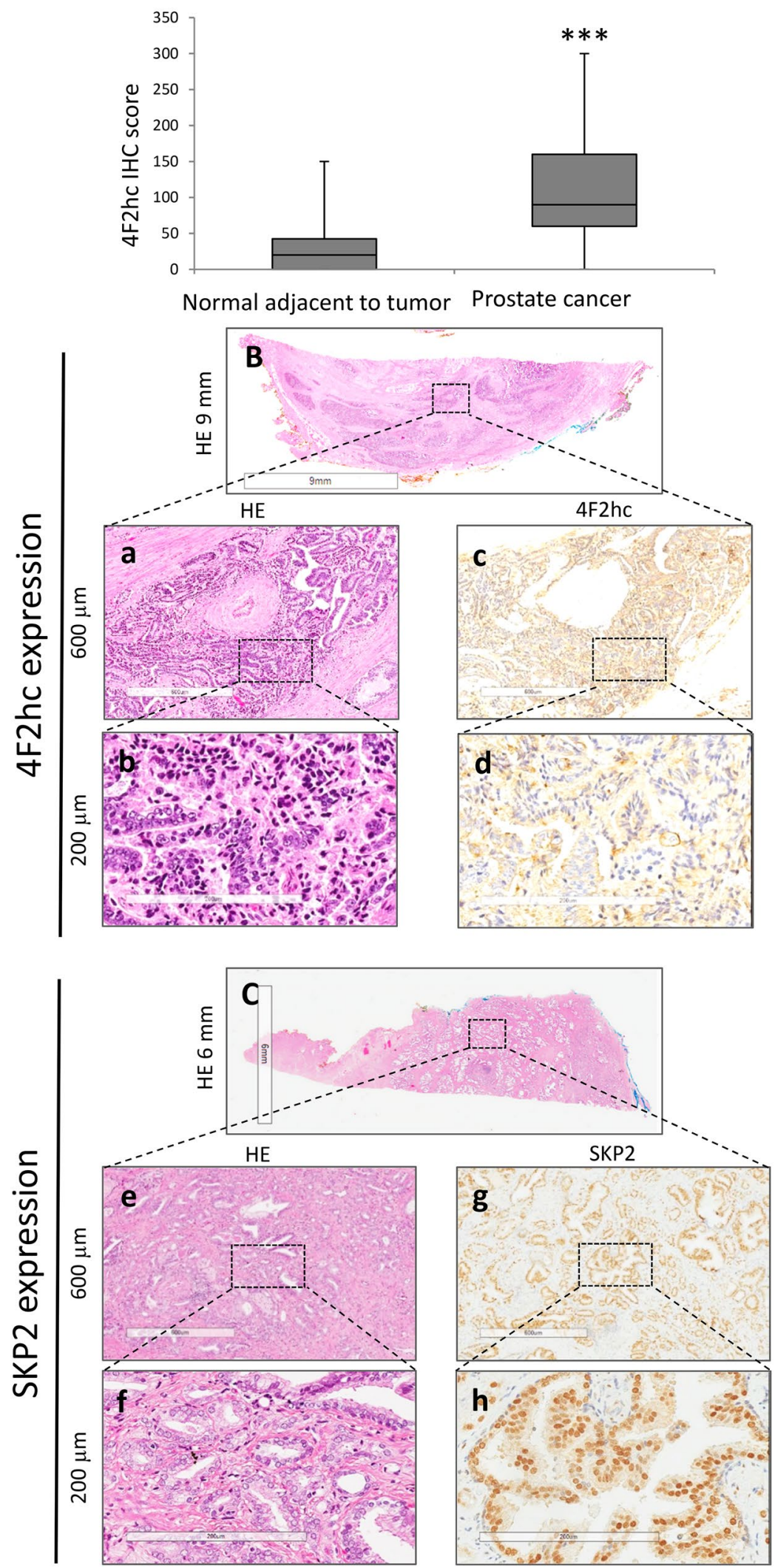

Figure 5. Representative staining pictures showing $4 \mathrm{~F} 2 \mathrm{hc}$ and SKP2 expression in PC tissues. Quantification of 4F2hc staining of NAT and PC tissues. The 4F2hc IHC scores levels are shown in normal prostate tissues and PC (A). 4F2hc and SKP2 expression in PC tissues was analysed by immunohistochemistry. Sections were stained with haematoxylin and eosin (B; a: $600 \mu \mathrm{m}$ and b: $200 \mu \mathrm{m}$ and C; e: $600 \mu \mathrm{m}$ and f: $200 \mu \mathrm{m})$. Representative images of $4 \mathrm{~F} 2 \mathrm{hc}$ immunohistochemical expression (c: $600 \mu \mathrm{m}$ and d: $200 \mu \mathrm{m}$ ) and representative images of SKP2 immunohistochemical expression (g: $600 \mu \mathrm{m}$ and h: $200 \mu \mathrm{m}$ ). Representative staining images are shown. 


\begin{tabular}{|l|l|}
\hline Clinical factor $(\mathbf{n}=\mathbf{8 2})$ & Median (range) or n $(\%)$ \\
\hline Age $(\mathrm{y})$ & $66(50-75)$ \\
\hline cT stage $(\mathrm{n})$ & $54(69.23 \%)$ \\
\hline 1 & $13(16.67 \%)$ \\
\hline 2 & $11(14.10 \%)$ \\
\hline 3 & $24(29.27 \%)$ \\
\hline GS $(\mathrm{n})$ & $37(45.12 \%)$ \\
\hline 6 & $12(14.63 \%)$ \\
\hline 7 & $9(10.98 \%)$ \\
\hline 8 & $4.64(0.42-10.9)$ \\
\hline 9 & $7.87(2.45-31.78)$ \\
\hline TST $(\mathrm{ng} / \mathrm{dL})$ & $0.30(0.06-1.44)$ \\
\hline PSA $(\mathrm{ng} / \mathrm{mL})$ & \\
\hline PSAD &
\end{tabular}

Table 1. Patients' characteristics. $c$ T stage $=$ clinical tumour stage, $\mathrm{GS}=$ Gleason score, $\mathrm{TST}=$ testosterone, PSA $=$ prostate-specific antigen, $\mathrm{PSAD}=\mathrm{PSA}$ density

$\beta 1$-dependent adhesion ${ }^{31}$. Because it is involved in cell growth, cell adhesion and other cellular activities. The light chain exhibits a function mainly in amino acid transport ${ }^{32}$. In addition to leucine import via amino acid transporter proteins LAT-1 and LAT-2, the light chain can also bind to $\mathrm{xCT}, \mathrm{y}^{+}$LAT1, $\mathrm{y}^{+}$LAT2 and asc1 $1^{33,34}$. Heterodimeric substrates differ in the survival and growth of many cell types. Importantly, the light chain cannot be expressed independently, the presence of the heavy chain is essential, and the isolated heavy chain can function independently in amino acid transport ${ }^{35}$. This specificity is shown in various cancers, such as: renal cancer ${ }^{27}$, Non-Small Cell Lung cancer ${ }^{36}$ and oral cancer ${ }^{37}$.

In previous studies, the oncogenic function of $4 \mathrm{~F} 2 \mathrm{hc}$ was demonstrated. Several groups reported that $4 \mathrm{~F} 2 \mathrm{hc}$ inhibits the proliferation of cancer cells by inhibiting the cell cycle. The FACS assay was performed in C4-2 cells. Si4F2hc effectively inhibited the S phase, with a significant increase in the G0/G1 period, suggesting cell cycle arrest. These data are consistent with two previous studies reporting the effect of $4 \mathrm{~F} 2 \mathrm{hc}$ on human osteosarcoma and thymic epithelial tumors ${ }^{24,38}$. 4F $2 \mathrm{hc}$ has been shown to affect cancer cell proliferation through the AKT, MAPK, and cell cycle related P21 and P27 signal pathways.

SKP2 is related to a cell cycle signal pathway. It is worth noting that overexpression of SKP2 is associated with the promotion and aggravation of many tumors ${ }^{39,40}$. The cell cycle signal pathway is activated in PC. Therefore, inhibition of SKP2 promotes the deterioration of cancer by targeting promotion of $\mathrm{p} 21$ and p27 and by cell senescence ${ }^{41}$. Reports show that overexpression of SkP2 coupled with under-expression of p27 is characteristic of $\mathrm{CRPC}^{42}$. In line with this evidence, the present data implicated the participation of SKP2 through alteration of the $\mathrm{S}$ phase of the cell cycle in the 4F2hc-related pathway. Previous studies demonstrated that mucin 1, mucin 16 , and mucin $5 \mathrm{~B}$ were the downstream genes of $4 \mathrm{~F} 2 \mathrm{hc}$ in gastric carcinoma cells ${ }^{43}$, although the effect of $4 \mathrm{~F} 2 \mathrm{hc}$ on transcription remains mostly unknown. In the present study, a comprehensive whole transcriptome shotgun sequencing analysis was conducted using the C4-2 PC cell line and Metascape gene analysis. The data showed that downregulated genes were markedly associated with the cell cycle, DNA replication, and cell division, and identified SKP-2 as a specific target gene among the downregulated genes in C4-2 cells.

Nevertheless, there are several limitations in this study. First, the data were obtained from a single institution, and the number of patients and the follow-up periods were limited. A prospective, multi-institutional study would be ideal to objectively assess the prognostic significance of $4 \mathrm{~F} 2 \mathrm{hc}$. Second, the mechanism of how $4 \mathrm{~F} 2 \mathrm{hc}$ regulates SKP2 remained to be identified. We are currently performing a chip assay to verify any direct association between two genes. Third, although the major binding partner of $4 \mathrm{~F} 2 \mathrm{hc}$ may be LAT1, the functional relationships with other transporters need to be determined.

Collectively, the present results suggest that, in line with its high expression frequency, 4F2hc may be a promising prognostic marker for PC patients. Thus, it is possible that high levels of 4F2hc expression, together with a high level of LAT1 expression, in surgical specimens may indicate the need to follow-up the patient carefully with frequent imaging in order to take precautions against recurrence.

\section{Materials and methods}

PC tissue specimens. A total of 82 clinical PC tissue samples were obtained from patients who underwent radical prostatectomy at Chiba University Hospital between 2006 and 2014. The present study was conducted in accordance with ethical standards that promote and ensure respect and integrity for all human subjects and the Declaration of Helsinki. All experiments were performed in accordance with relevant named guidelines and regulations. The study was approved by the Chiba University Review Board (approval number 408), and the patients signed a written, informed consent form.

Reagents and antibodies. In this study, siRNAs 4F2 cell-surface antigen heavy chain (si4F2hc) (Stealth siRNAs: HSS109825 and HSS109826), siRNAs S-Phase Kinase Associated Protein 2 (siSKP2) (Stealth siRNAs: HSS185711 and HSS109780), siRNA Negative Control (Stealth RNAi, Thermo Fisher Scientific, MA, USA), 
A

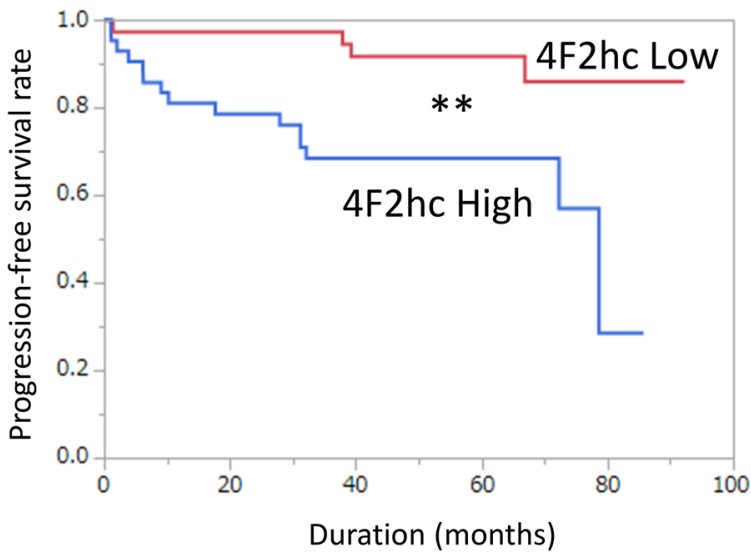

B

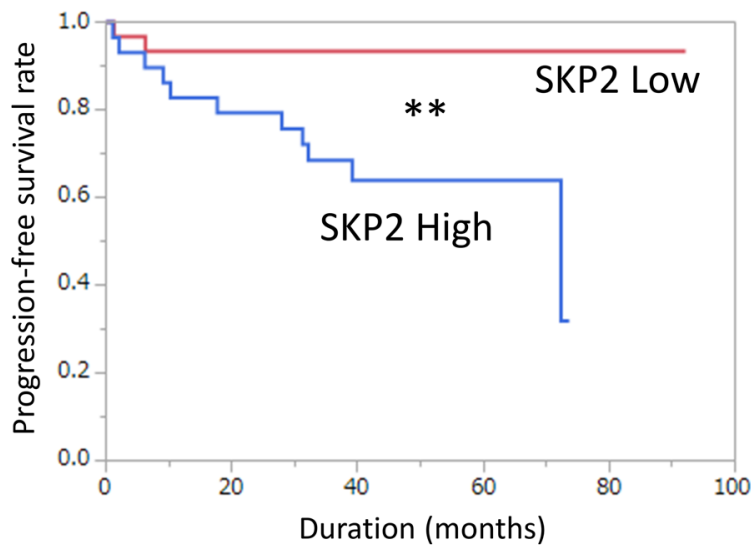

C

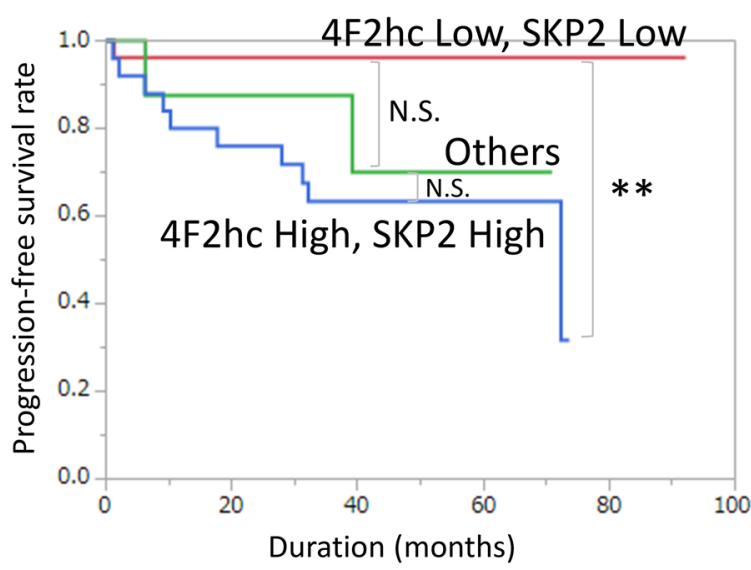

Figure 6. Progression-free survival of PC patients categorized by 4F2hc and SKP2 expression. Prognostic significance of 4F2hc expression for progression-free survival (PFS) (A), and prognostic significance of SKP2 expression for (PFS) (B). Prognostic significance of high 4F2hc/high SKP2 expression and low 4F2hc/low SKP2 expression, others are low 4F2hc/high SKP2 or high 4F2hc/low SKP2 (C). N.S. No significant difference. ${ }^{* *}$ $p<0.01$.

Lipofectamine 3000 Transfection Reagent (Invitrogen), were used. The antibodies used in the study were: anti4F2hc (CD98, Santa Cruz Biotechnology, TX, USA); anti-4F2hc (CD98, Trans Genic, Tokyo, Japan); anti-LAT1 (Trans Genic); anti-SKP2, anti-MAPK, anti-phosphorylated MAPK, anti-AKT, anti-phosphorylated AKT, antip21cip1, and anti-p27kip1 (Cell Signaling Technology, Danvers, MA, USA); Anti-GAPDH (Ambion, Waltham, CA, USA).

Cell culture and transfection. LNcap and C4-2 cell line were obtained from the American Type Culture Collection (Manassas, VA, USA). PC-3 cell line was obtained from the Cell Resource Canter for Biomedical Research, Institute of Development, Aging and Cancer Tohoku University (Sendai, Japan). DU145 cell line was obtained from the RIKEN Cell Bank (Tsukuba, Japan). PC cell lines were supplemented with 10\% foetal bovine 


\begin{tabular}{|l|l|l|l|l|l|l|l|l|}
\hline & \multicolumn{4}{|l}{ Univariate analysis } & \multicolumn{5}{l|}{ Multivariate analysis } \\
\cline { 2 - 11 } & Cut off & HR & $\mathbf{9 5 \%}$ CI & $\boldsymbol{P}$ & HR & $\mathbf{9 5 \%}$ CI & $\boldsymbol{P}$ & \\
\hline Age (y) & 66 & 0.96 & $0.37-2.43$ & 0.9281 & & & & \\
\hline cT stage & 2 & 4.86 & $1.84-14.16$ & 0.0014 & 4.22 & $1.64-18.73$ & 0.0280 & * \\
\hline GS & 7 & 3.06 & $1.00-13.25$ & 0.0488 & 1.78 & $0.24-36.35$ & 0.6028 & \\
\hline TST (ng/dL) & 4.64 & 0.69 & $0.26-1.76$ & 0.4364 & & & & \\
\hline PSA (ng/mL) & 7.90 & 1.74 & $0.70-4.51$ & 0.2284 & & & & \\
\hline 4F2hc Score & High/Low & 4.59 & $1.65-16.25$ & 0.0027 & 11.54 & $1.16-276.67$ & 0.0357 & * \\
\hline LAT1 Score & High/Low & 2.68 & $0.87-11.64$ & 0.0886 & & & & \\
\hline SKP2 Score & High/Low & 6.92 & $1.83-45.07$ & 0.0029 & 0.73 & $0.14-6.99$ & 0.7534 & \\
\hline
\end{tabular}

Table 2. Predictors of progression-free survival. $\mathrm{HR}=\mathrm{Cox}$ proportional hazard ratio, $95 \% \mathrm{CI}=95 \%$ confidence interval, $c$ T stage $=$ clinical tumour stage, GS $=$ Gleason score, TST $=$ testosterone, $\mathrm{PSA}=$ prostatespecific antigen. ${ }^{\star}$ Statistical significance $(p<0.05)$.

\begin{tabular}{|l|l|l|l|l|}
\hline & 4F2hc Low & 4F2hc High & P & \\
\hline Age (y) & $64.50 \pm 5.25$ & $66.50 \pm 5.20$ & 0.0162 & * \\
\hline cT stage (n) & & & 0.0255 & * \\
\hline 1 & 29 & 25 & & \\
\hline 2 & 5 & 8 & & \\
\hline 3 & 2 & 9 & & \\
\hline GS (n) & & & 0.0035 & * \\
\hline 6 & 17 & 7 & & \\
\hline 7 & 19 & 18 & & \\
\hline 8 & 3 & 9 & & \\
\hline 9 & 1 & 8 & & \\
\hline TST (ng/dL) & $4.66 \pm 1.92$ & $4.64 \pm 1.78$ & 0.1661 & \\
\hline PSA (ng/mL) & $7.46 \pm 6.37$ & $8.30 \pm 6.57$ & 0.3781 & \\
\hline PSAD & $0.27 \pm 0.23$ & $0.30 \pm 0.31$ & 0.1156 & \\
\hline
\end{tabular}

Table 3. Comparison of clinical factors between $4 \mathrm{~F} 2 \mathrm{hc}$ Low and $4 \mathrm{~F} 2 \mathrm{hc}$ High groups. Data are expressed as means \pm standard deviation unless otherwise indicated. $\mathrm{cT}$ stage $=$ clinical tumour stage, $\mathrm{GS}=\mathrm{Gleason}$ score, TST $=$ testosterone, PSA $=$ prostate-specific antigen, PSAD $=$ PSA density. ${ }^{\star}$ Statistical significance $(p<0.05)$.

\begin{tabular}{|l|l|l|l|l|}
\hline & SKP2 Low & SKP2 High & P & \\
\hline Age $(\mathrm{y})$ & $64.23 \pm 5.47$ & $66.57 \pm 5.33$ & 0.0998 & \\
\hline cT stage (n) & & & 0.0277 & $*$ \\
\hline 1 & 25 & 16 & & \\
\hline 2 & 2 & 8 & & \\
\hline 3 & 2 & 5 & & \\
\hline GS $(\mathrm{n})$ & & & 0.0138 & $*$ \\
\hline 6 & 13 & 6 & & \\
\hline 7 & 14 & 13 & & \\
\hline 8 & 1 & 6 & & \\
\hline 9 & 2 & 5 & & \\
\hline TST $(\mathrm{ng} / \mathrm{dL})$ & $5.38 \pm 1.87$ & $4.51 \pm 1.74$ & 0.0984 & \\
\hline PSA (ng/mL) & $8.68 \pm 4.78$ & $12.06 \pm 7.70$ & 0.0458 & $*$ \\
\hline PSAD & $0.30 \pm 0.19$ & $0.43 \pm 0.29$ & 0.0360 & $*$ \\
\hline
\end{tabular}

Table 4. Comparison of clinical factors between SKP2 Low and SKP2 High groups. Data are expressed as means \pm standard deviation unless otherwise indicated. $c T$ stage $=$ clinical tumour stage, $\mathrm{GS}=$ Gleason score, TST $=$ testosterone, PSA $=$ prostate-specific antigen, PSAD $=$ PSA density. ${ }^{\star}$ Statistical significance $(p<0.05)$. 
serum (FBS) in RPMI 1640 culture medium and maintained in a humidified atmosphere incubator (95\% air, 5\% $\mathrm{CO}_{2}, 37^{\circ} \mathrm{C}$ ). Lipofectamine RNAiMAX reagent (Invitrogen) was used, and siRNA was transfected with PC cells. Detailed experimental methods have been previously reported ${ }^{34}$.

mRNA expression evaluation. Total RNA was isolated using the RNeasy Mini Kit. cDNA was synthesized with the ImProm-II Reverse (Promega, Madison, WI, USA). mRNA expression was carried out as described previously ${ }^{34}$ with ABI 7300 (Applied Biosystems, Foster, CA, USA) and SYBR Green PCR Master Mix (QPS-201, Toyobo, Japan). GAPDH (internal control) and PCR primers used in this study are listed in Table S2.

Western blot analysis. Protein expression levels were measured using GAPDH as the control. Protein samples $(24 \mathrm{mg}$ ) were subjected to SDS-PAGE and transferred to Hybond-C membranes (GE Healthcare, Chicago, IL, USA). The membranes were then blocked ( $\%$ skim milk, $\left.30 \mathrm{~min}, 37^{\circ} \mathrm{C}\right)$. The primary antibody was incubated overnight at $4^{\circ} \mathrm{C}$. Detailed experimental methods have been previously reported ${ }^{34}$. Western blotting's uncropped data is in the supplementary information.

Immunohistochemistry (IHC). Immunohistochemistry procedures were performed according to a previously described method ${ }^{34}$. The slides were treated with endogenous peroxidase ( $30 \%$ hydrogen peroxide solution, $100 \%$ methanol, $10 \mathrm{~min})$, and then incubated with anti-4F2hc and anti-SKP2 $\left(4{ }^{\circ} \mathrm{C}\right.$ overnight). Finally, the slides were lightly counterstained with haematoxylin, dehydrated with ethanol, cleared with xylene, and mounted.

IHC scores were as follows: 3 intense staining; 2 moderate; 1 very weak; and 0 no staining. IHC scores were calculated as follows: IHC score $=3 \times$ (mean percentage of intensely stained cells in the field $)+2 \times($ mean percentage of moderately stained cells in the field $)+1 \times$ (mean percentage of weakly stained cells in the field). Two independent investigators blinded to patient clinical status scored each specimen.

Growth assay, cell migration, and invasion assay. Detailed experimental methods have been previously reported ${ }^{34}$. Following the manufacturers' instructions, the migration assay was performed using the Cell Counting Kit-8 (343-07,623, Dojindo, Japan) and the Falcon Permeable Support Plate (353,097, Corning, NY, USA), and the invasion assay used the Matrigel invasion chamber (354,480, Corning). Cell migration and invasion assays were performed using the Diff-Quik kit (16,920, Funakoshi Co, Tokyo, Japan). Cell migration activity was also evaluated with wound healing assays. C4-2 and DU145 cells $\left(2 \times 10^{5}\right)$ were plated in 6-well plates and incubated for $48 \mathrm{~h}$ with $10 \mu \mathrm{g} / \mathrm{ml}$ mitomycin C solution (20,898-21, Nacalai Tesque, Kyoto, Japan). Scraping cell monolayers with P-20 micropipette tips. The initial gap length $(0 \mathrm{~h})$ and the residual gap length $(24 \mathrm{~h})$ after wounding were calculated from the micrographs.

Flow cytometric analysis. For cell cycle analysis, cells were stained with propidium iodide using the FITC BrdU Flow Kit (51-2359KC, BD Biosciences, Bedford, MA, USA) according to the manufacturer's instructions and examined using the FACS Celesta Analyzer (660,344, BD Biosciences). Flow cytometry data were analysed using FlowJo using the previously reported flow cytometric method ${ }^{34}$.

RNA sequencing. In order to examine the downstream signal of $4 \mathrm{~F} 2 \mathrm{hc}$, RNA sequencing was performed based on previous reports ${ }^{34}$, using the SMART-Seq v4 Ultra Low Input RNA Kit (Clontech, Palo Alto, CA, USA), NEBNext Ultra DNA Library Prep Kit (New England Biolabs, Ipswich, MA, USA), HiSeq 1500 system (Illumina, Santiago, CA, USA), and Cuffdiff (Cufflinks version 2.2.1).

Statistical analysis. The Kaplan-Meier method and univariate and multivariate Cox proportional models were used for statistical analyses. Mathematical calculations were performed using JMP Pro 15 (SAS Institute, Cary, NC, USA). The Cancer Genome Atlas (TCGA) (https://www.cancer.gov/) was obtained through Oncomine (https://www.oncomine.org).

Received: 20 November 2020; Accepted: 5 May 2021

Published online: 01 June 2021

\section{References}

1. Lowrance, W. T. et al. Castration-resistant prostate cancer: AUA guideline amendment 2018. J. Urol. 200, 1264-1272. https://doi. org/10.1016/j.juro.2018.07.090 (2018).

2. Chen, Z. et al. Androgen receptor-activated enhancers simultaneously regulate oncogene TMPRSS2 and lncRNA PRCAT38 in prostate cancer. Cells. https://doi.org/10.3390/cells8080864 (2019).

3. Knudsen, K. E. \& Scher, H. I. Starving the addiction: New opportunities for durable suppression of AR signaling in prostate cancer. Clin. Cancer Res. 15, 4792-4798. https://doi.org/10.1158/1078-0432.Ccr-08-2660 (2009).

4. Watson, P. A., Arora, V. K. \& Sawyers, C. L. Emerging mechanisms of resistance to androgen receptor inhibitors in prostate cancer. Nat. Rev. Cancer 15, 701-711. https://doi.org/10.1038/nrc4016 (2015).

5. Ryan, C. J. et al. Abiraterone in metastatic prostate cancer without previous chemotherapy. N. Engl. J. Med. 368, 138-148. https:// doi.org/10.1056/NEJMoa1209096 (2013).

6. de Bono, J. S. et al. Abiraterone and increased survival in metastatic prostate cancer. N. Engl. J. Med. 364, 1995-2005. https://doi. org/10.1056/NEJMoa1014618 (2011). 
7. Scher, H. I. et al. Increased survival with enzalutamide in prostate cancer after chemotherapy. N. Engl. J. Med. 367, 1187-1197. https://doi.org/10.1056/NEJMoa1207506 (2012).

8. Ryan, C. J. et al. Abiraterone acetate plus prednisone versus placebo plus prednisone in chemotherapy-naive men with metastatic castration-resistant prostate cancer (COU-AA-302): Final overall survival analysis of a randomised, double-blind, placebo-controlled phase 3 study. Lancet Oncol. 16, 152-160. https://doi.org/10.1016/s1470-2045(14)71205-7 (2015).

9. Beer, T. M. et al. Enzalutamide in metastatic prostate cancer before chemotherapy. N. Engl. J. Med. 371, 424-433. https://doi.org/ 10.1056/NEJMoa1405095 (2014)

10. Kaira, K. et al. Prognostic significance of L-type amino-acid transporter 1 expression in surgically resected pancreatic cancer. $B r$. J. Cancer 107, 632-638. https://doi.org/10.1038/bjc.2012.310 (2012).

11. Hayase, S. et al. L-type amino acid transporter 1 expression is upregulated and associated with cellular proliferation in colorectal cancer. Oncol. Lett. 14, 7410-7416. https://doi.org/10.3892/ol.2017.7148 (2017).

12. Cormerais, Y. et al. The glutamine transporter ASCT2 (SLC1A5) promotes tumor growth independently of the amino acid transporter LAT1 (SLC7A5). J. Biol. Chem. 293, 2877-2887. https://doi.org/10.1074/jbc.RA117.001342 (2018).

13. Oxender, D. L. \& Christensen, H. N. Evidence for two types of mediation of neutral and amino-acid transport in Ehrlich cells. Nature 197, 765-767. https://doi.org/10.1038/197765a0 (1963).

14. Kanai, Y. et al. Expression cloning and characterization of a transporter for large neutral amino acids activated by the heavy chain of 4F2 antigen (CD98). J. Biol. Chem. 273, 23629-23632. https://doi.org/10.1074/jbc.273.37.23629 (1998).

15. Salisbury, T. B. \& Arthur, S. The regulation and function of the L-type amino acid transporter 1 (LAT1) in cancer. Int. J. Mol. Sci.. https://doi.org/10.3390/ijms19082373 (2018).

16. Oda, K. et al. L-type amino acid transporter 1 inhibitors inhibit tumor cell growth. Cancer Sci. 101, 173-179. https://doi.org/10. 1111/j.1349-7006.2009.01386.x (2010).

17. Kaira, K. et al. Expression of L-type amino acid transporter 1 (LAT1) in neuroendocrine tumors of the lung. Pathol. Res. Pract. 204, 553-561. https://doi.org/10.1016/j.prp.2008.02.003 (2008).

18. Furuya, M., Horiguchi, J., Nakajima, H., Kanai, Y. \& Oyama, T. Correlation of L-type amino acid transporter 1 and CD98 expression with triple negative breast cancer prognosis. Cancer Sci. 103, 382-389. https://doi.org/10.1111/j.1349-7006.2011.02151.x (2012).

19. Xu, M. et al. Up-Regulation of LAT1 during antiandrogen therapy contributes to progression in prostate cancer cells. J. Urol. 195, 1588-1597. https://doi.org/10.1016/j.juro.2015.11.071 (2016).

20. Satoh, T. et al. Prognostic significance of the expression of CD98 (4F2hc) in gastric cancer. Anticancer Res. 37, 631-636. https:// doi.org/10.21873/anticanres.11357 (2017).

21. Kaira, K. et al. Expression of amino acid transporter (LAT1 and 4F2hc) in pulmonary pleomorphic carcinoma. Hum. Pathol. 84, 142-149. https://doi.org/10.1016/j.humpath.2018.09.020 (2019).

22. Kaira, K. et al. Expression of 4F2hc (CD98) in pulmonary neuroendocrine tumors. Oncol. Rep. 26, 931-937. https://doi.org/10. 3892/or.2011.1384 (2011).

23. Sugiura, M. et al. Identification of AR-V7 downstream genes commonly targeted by AR/AR-V7 and specifically targeted by AR-V7 in castration resistant prostate cancer. Transl. Oncol. 14, 100915. https://doi.org/10.1016/j.tranon.2020.100915 (2020).

24. Zhu, B. et al. SLC3A2 is upregulated in human osteosarcoma and promotes tumor growth through the PI3K/Akt signaling pathway. Oncol. Rep. 37, 2575-2582. https://doi.org/10.3892/or.2017.5530 (2017).

25. Toyoda, M. et al. CD98 as a novel prognostic indicator for patients with stage III/IV hypopharyngeal squamous cell carcinoma. Head Neck 37, 1569-1574. https://doi.org/10.1002/hed.23797 (2015).

26. Toyoda, M. et al. Prognostic significance of amino-acid transporter expression (LAT1, ASCT2, and xCT) in surgically resected tongue cancer. Br. J. Cancer 110, 2506-2513. https://doi.org/10.1038/bjc.2014.178 (2014).

27. Fotiadis, D., Kanai, Y. \& Palacin, M. The SLC3 and SLC7 families of amino acid transporters. Mol. Asp. Med. 34, 139-158. https:// doi.org/10.1016/j.mam.2012.10.007 (2013).

28. Wang, Q. et al. Targeting amino acid transport in metastatic castration-resistant prostate cancer: Effects on cell cycle, cell growth, and tumor development. J. Natl Cancer Inst. 105, 1463-1473. https://doi.org/10.1093/jnci/djt241 (2013).

29. Gabrisko, M. \& Janecek, S. Looking for the ancestry of the heavy-chain subunits of heteromeric amino acid transporters rBAT and 4F2hc within the GH13 alpha-amylase family. FEBS J. 276, 7265-7278. https://doi.org/10.1111/j.1742-4658.2009.07434.x (2009).

30. Kolesnikova, T. V., Mannion, B. A., Berditchevski, F. \& Hemler, M. E. Betal integrins show specific association with CD 98 protein in low density membranes. BMC Biochem. 2, 10. https://doi.org/10.1186/1471-2091-2-10 (2001)

31. $\mathrm{Wu}, \mathrm{B}$. et al. Basigin-mediated redistribution of $\mathrm{CD} 98$ promotes cell spreading and tumorigenicity in hepatocellular carcinoma. $J$ Exp Clin. Cancer Res CR 34, 110. https://doi.org/10.1186/s13046-015-0226-6 (2015).

32. Devés, R. \& Boyd, C. A. Surface antigen CD98(4F2): Not a single membrane protein, but a family of proteins with multiple functions. J. Membr. Biol. 173, 165-177. https://doi.org/10.1007/s002320001017 (2000).

33. Palacín, M. A new family of proteins ( $\mathrm{BBAT}$ and $4 \mathrm{~F} 2 \mathrm{hc}$ ) involved in cationic and zwitterionic amino acid transport: A tale of two proteins in search of a transport function. J. Exp. Biol. 196, 123-137 (1994).

34. Maimaiti, M. et al. Expression of L-type amino acid transporter 1 as a molecular target for prognostic and therapeutic indicators in bladder carcinoma. Sci. Rep. 10, 1292. https://doi.org/10.1038/s41598-020-58136-x (2020).

35. Cantor, J. M. \& Ginsberg, M. H. CD98 at the crossroads of adaptive immunity and cancer. J. Cell Sci. 125, 1373-1382. https://doi. org $/ 10.1242 /$ jcs.096040 (2012).

36. Pan, D. et al. Preferential localization of MUC1 glycoprotein in exosomes secreted by non-small cell lung carcinoma cells. Int. J. Mol. Sci. https://doi.org/10.3390/ijms20020323 (2019).

37. Liang, J. \& Sun, Z. Overexpression of membranal SLC3A2 regulates the proliferation of oral squamous cancer cells and affects the prognosis of oral cancer patients. J. Oral. Pathol. Med. https://doi.org/10.1111/jop.13132 (2020).

38. Kaira, K. et al. CD98 expression is associated with the grade of malignancy in thymic epithelial tumors. Oncol. Rep. 24, 861-867. https://doi.org/10.3892/or.2010.861 (2010).

39. Liang, Y. et al. Skp2 expression unfavorably impacts survival in resectable esophageal squamous cell carcinoma. J. Transl. Med. 10, 73. https://doi.org/10.1186/1479-5876-10-73 (2012).

40. Calvisi, D. F. et al. SKP2 and CKS1 promote degradation of cell cycle regulators and are associated with hepatocellular carcinoma prognosis. Gastroenterology 137, 1816-1826.e1811-1810. https://doi.org/10.1053/j.gastro.2009.08.005 (2009).

41. Chu, I. M., Hengst, L. \& Slingerland, J. M. The Cdk inhibitor p27 in human cancer: Prognostic potential and relevance to anticancer therapy. Nat. Rev. Cancer 8, 253-267. https://doi.org/10.1038/nrc2347 (2008).

42. Zhao, H. et al. p27T187A knockin identifies Skp2/Cks1 pocket inhibitors for advanced prostate cancer. Oncogene 36, 60-70. https:// doi.org/10.1038/onc.2016.175 (2017).

43. Wang, S. et al. SLC3A2, antigen of $\mathrm{mAb} 3 \mathrm{G} 9$, promotes migration and invasion by upregulating of mucins in gastric cancer. Oncotarget 8, 88586-88598. https://doi.org/10.18632/oncotarget.19529 (2017).

\section{Acknowledgements}

The present work was supported by a Grant-in-Aid for Scientific Research(C) (grant \#25462469) to S. Sakamoto. The authors declare no conflict of interest. 


\section{Author contributions}

M.M. and S.S. designed the study; M.M., A.K. and S.S. performed experiments; A.Y., M.K., X.M., A.K., W.K., N.K. and I.Y. contributed new reagents; M.M., S.M. and K.M. analysed data; M.M., S.S., K.Y., K.A., I.Y., I.J., A.N., and I.T. wrote the paper. All authors read and approved the final manuscript.

\section{Competing interests}

The authors declare no competing interests.

\section{Additional information}

Supplementary Information The online version contains supplementary material available at https:/doi.org/ 10.1038/s41598-021-90748-9.

Correspondence and requests for materials should be addressed to S.S.

Reprints and permissions information is available at www.nature.com/reprints.

Publisher's note Springer Nature remains neutral with regard to jurisdictional claims in published maps and institutional affiliations.

Open Access This article is licensed under a Creative Commons Attribution 4.0 International License, which permits use, sharing, adaptation, distribution and reproduction in any medium or format, as long as you give appropriate credit to the original author(s) and the source, provide a link to the Creative Commons licence, and indicate if changes were made. The images or other third party material in this article are included in the article's Creative Commons licence, unless indicated otherwise in a credit line to the material. If material is not included in the article's Creative Commons licence and your intended use is not permitted by statutory regulation or exceeds the permitted use, you will need to obtain permission directly from the copyright holder. To view a copy of this licence, visit http://creativecommons.org/licenses/by/4.0/.

(C) The Author(s) 2021 